\title{
Absence of linkage of Noonan syndrome to the neurofibromatosis type 1 locus
}

\author{
M Sharland, R Taylor, M A Patton, S Jeffery
}

\begin{abstract}
Eleven families with Noonan syndrome in either two or three generations have been identified. Following the reports of subjects with features of both Noonan syndrome and neurofibromatosis type 1 , these pedigrees have been studied using a number of probes at the neurofibromatosis type 1 locus (17q11). A significantly negative lod score was obtained with the intragenic probe NF1-C2, suggesting that the genes for Noonan syndrome and neurofibromatosis type 1 are not contiguous.
\end{abstract}

Noonan syndrome is a condition characterised by short stature, dysmorphic facies, and congenital heart disease. Following the original paper by Noonan and Ehmke, ${ }^{1}$ it has been recognised that Noonan syndrome is a major cause of congenital heart disease, and is inherited as an autosomal dominant trait. ${ }^{2}$ The Noonan syndrome phenotype becomes less obvious with age, ${ }^{3}$ and clear familial transmission can be established in only a proportion of cases. ${ }^{4}$ In other families, Noonan syndrome in the child may arise either as the result of a new mutation or be inherited from an affected parent. Because of the variability of the adult phenotype, it is very difficult to discriminate between these possibilities in a proportion of families attending for genetic counselling. The localisation and subsequent cloning of the gene for Noonan syndrome would be of great benefit both for providing genetic counselling to families, and to aid understanding of the pathogenesis of the condition.

Sporadic cases of apparent Noonan syndrome have been described with varying chromosomal rearrangements, ${ }^{5-7}$ but none of the reported cases has had a classical Noonan syndrome phenotype. Watson ${ }^{8}$ originally described three families with the combination of valvular pulmonary stenosis, dull intelligence, and café au lait spots, ${ }^{8}$ in whom subsequent analysis has shown linkage to the neurofibromatosis type 1 locus. ${ }^{9}$ The association of neurofibromatosis type 1 with a Noonan syndrome phenotype was then extended by Allanson et $a l,{ }^{10}$ and the possible causes of the association have been clearly summarised by Opitz et al. ${ }^{11}$ At least 11 further cases have been reported of subjects with both neurofibromatosis type 1 and Noonan syndrome. ${ }^{12-14}$ One family is particularly convincing, ${ }^{14}$ consisting of an 18 year old man with both the classical features of Noonan syndrome and neurofibromatosis type
1 , and his father with definite neurofibromatosis type 1 and a mild Noonan syndrome phenotype. One possible cause of this close association is that the genes for Noonan syndrome and neurofibromatosis type 1 are contiguous, and that a large deletion involving both genes produces the combined phenotype. In this first report of linkage analysis in Noonan syndrome, we therefore studied families with Noonan syndrome and no clinical evidence of neurofibromatosis, with a number of probes from the neurofibromatosis type 1 locus on chromosome 17q11.

\section{Materials and methods} FAMILY SAMPLE

As part of a clinical and genetic study of Noonan syndrome, over 100 families have been seen at St George's Hospital, London. Detailed pedigrees were obtained and all available first degree relatives of the proband were carefully examined for clinical stigmata of Noonan syndrome. From these families, 11 pedigrees were selected where subjects with Noonan syndrome could be clearly identified in either two or three generations. In each of these pedigrees, the child proband had classical features of Noonan syndrome, a normal karyotype, and was also diagnosed as having Noonan syndrome on the scoring system devised by Duncan et al. ${ }^{15}$ The diagnosis was made in the adult cases on clinical evaluation of a typical Noonan syndrome phenotype. Echocardiography was performed on all subjects with an abnormal cardiac examination. The pedigrees are shown in the figure. The pedigree structures confirm autosomal dominant inheritance.

\section{DNA ANALYSIS}

DNA was extracted from 10 to $20 \mathrm{ml}$ of EDTA blood by the method of Kunkel et al. ${ }^{16}$ Each DNA sample was digested with the appropriate restriction enzyme as recommended in the manufacturers' instructions (Anglian). After digestion, the sample was electrophoresed in a $1 \%$ agarose gel in TBE buffer. The DNA was transferred from the gel to a nylon membrane (Hybond N, Amersham) using the method of Southern. ${ }^{17}$ Filters were then prehybridised in $0.5 \mathrm{~mol} / 1$ phosphate buffer, $\mathrm{pH} 7 \cdot 0 / 7 \%$ SDS solution at $65^{\circ} \mathrm{C}$. Hybridisation was performed using probes labelled with ${ }^{32} \mathrm{P}$ [dCTP] (NEN/ DuPont) by the random primer method ${ }^{18}$ at $65^{\circ} \mathrm{C}$ for 16 hours. The filters were then washed to a stringency of $1 \times \mathrm{SSC}, 0 \cdot 1 \%$ SDS for 20 minutes at $65^{\circ} \mathrm{C}$ and were autoradiographed for one to three days at $-70^{\circ} \mathrm{C}$. 

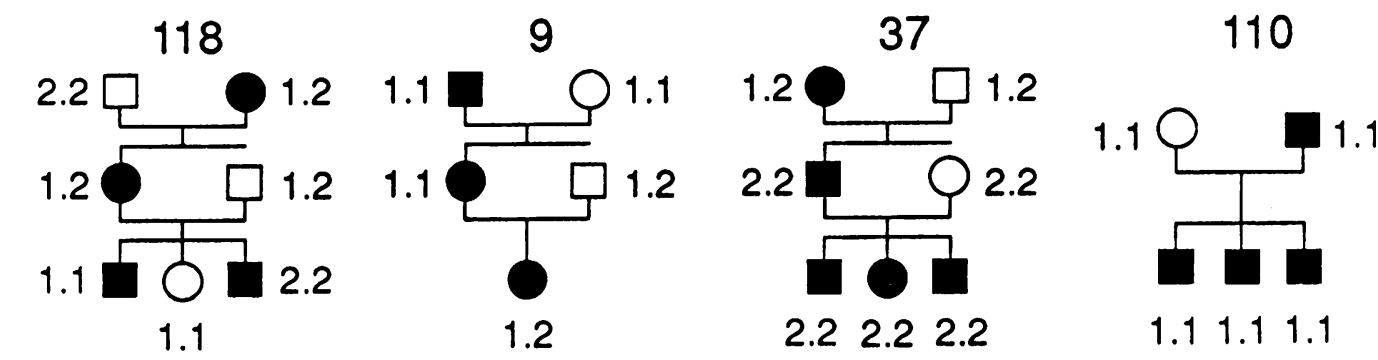

51

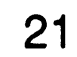

41

1.11 .11 .1

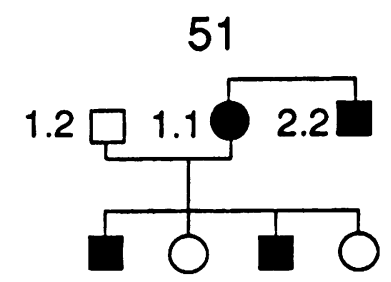

$\begin{array}{llll}1.2 & 1.2 & 1.1 & 1.2\end{array}$
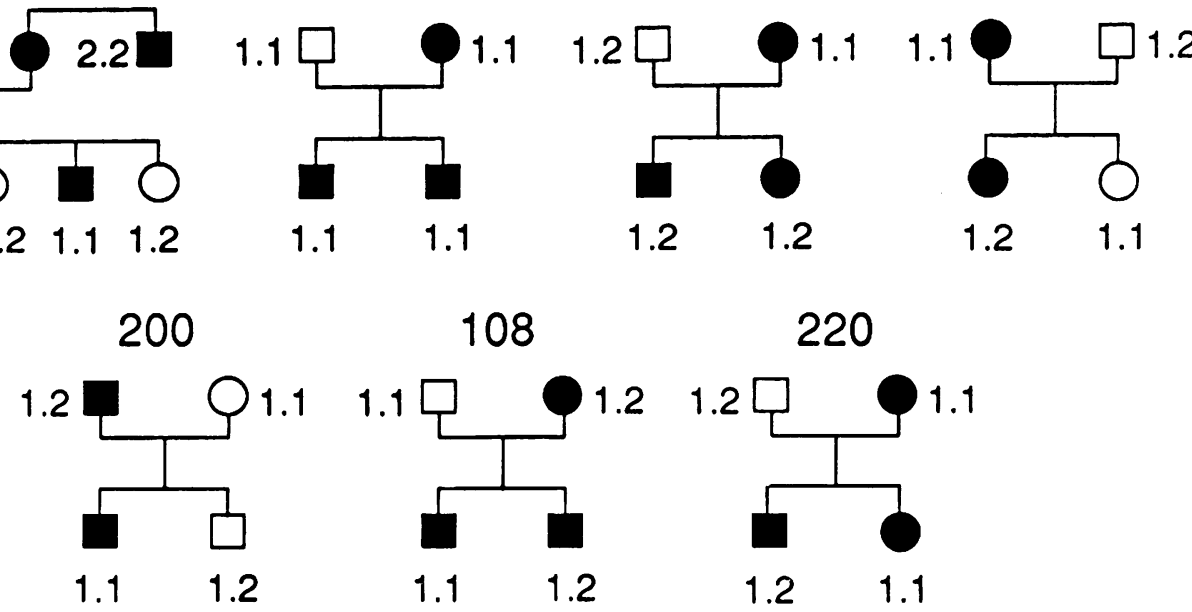

Pedigrees showing affected status and NF1-C2 allelic distribution.

The probes used were THH32, EW204, EW206, and EW207. Unfortunately, all of these probes were uninformative in all of the pedigrees available. We subsequently obtained the intragenic probe NF1-C2, recognising an $E c o$ RI polymorphism with alleles at 9.5 and $7 \cdot 3 \mathrm{~kb},{ }^{19}$ which was kindly provided by $\mathrm{Dr} F$ Collins.

\section{LINKAGE ANALYSIS}

The marker data for all pedigrees using NF1$\mathrm{C} 2$ is shown in the figure. Of the 11 families studied, three showed recombination events. A two point lod score analysis was carried out using the program LINKAGE,$^{20}$ to test the possible association of Noonan syndrome with RFLP alleles generated by NF1-C2. A gene frequency of 1 in 2000 was assumed. At $\theta=0.05$ a lod of -2.91 was generated.

\section{Discussion}

In only $10 \%$ of the families seen was the clinical phenotype sufficiently clear in all generations to enable accurate assessment of each subject's phenotypic status to be made. In the majority of families, two or more children were affected. The cardiac lesion in all affected members was dysplastic pulmonary stenosis. No subjects with hypertrophic cardiomyopathy were included. No patient had any clinical evidence of neurofibromatosis type 1 . When the segregation of the NF1-C2 alleles and Noonan syndrome is considered, a significantly negative lod score is obtained from the pedigrees. This study suggests that the gene for Noonan syndrome in these families is not closely linked to the neurofibromatosis locus on 17q11.2. There are a number of explanations for this finding.

Subjects with both neurofibromatosis and a convincing Noonan syndrome phenotype are rare. A significant number of patients with neurofibromatosis type 1 have an altered body habitus that clinically overlaps with Noonan syndrome. ${ }^{21}$ Out of the 150 subjects with Noonan syndrome we have seen in our clinical project, only two sporadic cases had any signs of both Noonan syndrome and neurofibromatosis type 1. However, two families studied with both neurofibromatosis type 1 and a mild Noonan phenotype appear to have large scale mutations in the neurofibromatosis gene ( $T$ Strachan, personal communication). It is possible that a large deletion in the neurofibromatosis gene produces an alteration in the gene product that may have an effect on fetal development, causing a Noonan-like phenotype.

A further explanation of the absence of linkage is that Noonan syndrome is a genetically heterogeneous condition. A wide variation in the clinical picture of Noonan syndrome is recognised, both within and between families. We have, however, been impressed by the clinical similarity of children from different families at the same age. We have not been able to identify subgroups of Noonan syndrome within our patient group as yet, but it is still possible that in some families the gene for Noonan syndrome is linked to the neurofibromatosis type 1 locus.

The most likely explanation of these findings, however, is that the locus of the gene for Noonan syndrome is not at $17 \mathrm{q} 11$, and further linkage studies are required to locate the gene for this autosomal dominant condition. 
1 Noonan JA, Ehmke DA. Associated noncardiac malforma1963;63:468-70.

2 Mendez HMM, Opitz JM. Noonan syndrome: a review. Am F Med Genet 1985;21:493-506.

3 Allanson JE, Hall JG, Hughes HE, Preus M, Witt RD. Noonan syndrome: the changing phenotype. $\mathrm{Am} \mathrm{f} \mathrm{Med}$ Geonan syndrome: the 4 Allanson JE. Noonan syndrome. F Med Genet 1987;24:9-13. Onufer CN, Stephan MJ, Thuline HC, Char F. Chromosome 13 long arm interstitial deletion associated with features of Noonan phenotype. Ann Genet (Paris

6 Carballin MR, Miro R, Egozcue J. Abnormal phenotype in a child with the same balanced translocation $(5 ; 7)(\mathrm{p} 15 ; \mathrm{q} 22)$ as his father. Clin Genet 1981;20:428-31.

7 Jenkins MB, Stang HJ, Davis E, Boyd L. Deletion of the proximal long arm of chromosome 3 in an infant with features of Turner syndrome. Ann Genet (Paris) 1985;28:42-4

8 Watson GH. Pulmonary stenosis, café-au-lait spots and dull intelligence. Arch Dis Child 1967;42:303-7.

9 Upadhyaya M, Sarfarazi N, Broadhead W, et al. Linkage of Watson syndrome to chromosome 17 markers. Cytogenet Cell Genet 1989;51:1094.

10 Allanson JE, Hall JG, Van Allen MI. Noonan phenotype associated with neurofibromatosis. Am $7 \mathrm{Med}$ Genet 1985;21:463-70

11 Opitz JM, Weaver DD. Editorial comment: the neurofibromatosis-Noonan syndrome. $\mathrm{Am} \mathcal{f} \mathrm{Med}$ Genet 1985;21:477-90.
12 Kaplan P, Rosenblatt B. A distinctive facial appearance in neurofibromatosis von Recklinghausen. Am $\mathcal{f}$ Med Genet 1985;21:463-70.

13 Mendez HMM. The neurofibromatosis-Noonan syndrome. Am $\mathcal{F}$ Med Genet 1985;21:471-6.

14 Abuelo DN, Meryash DL. Neurofibromatosis with fully expressed Noonan syndrome. Am $\mathcal{f}$ Med Genet 1988;29:937-41.

15 Duncan WJ, Fowler RS, Farkas LG, et al. A comprehensive scoring system for evaluating Noonan syndrome. $\mathrm{Am}$ f Med Genet 1981;10:37-50.

16 Kunkel LM, Tantravahi U, Eisenhard M, Latt SA. Regional localisation on the human $\mathrm{X}$ of DNA segments cloned from flow sorted chromosomes. Nucleic Acids Res 1982;10:1557-8.

17 Southern EM. Detection of specific sequences among DNA fragments separated by gel electrophoresis. $\mathcal{f} \mathrm{Mol}$ Biol 1975.98.503-17.

18 Feinberg AP, Vogelstein B. Addendum to A technique for radiolabelling DNA restriction endonuclease fragments to a high specific activity. Anal Biochem 1984;137:266.

19 Wallace MR, Marchuk DA, Anderson LB, et al. Type 1 neurofibromatosis gene: identification of a large transcript disrupted in three NF1 patients. Science 1990;249:181-6.

20 Lathrop GM, Lalouel JM, Julier C, Ott J. Strategies for multilocus linkage analysis in humans. Proc Natl Acad Sci multilocus linkage analy

21 Riccardi VM, Eichner JE. Neurofibromatosis: phenotype, natural history, and pathogenesis. Baltimore: The Johns Hopkins University Press, 1986. 